\title{
O DIÁLOGO ENTRE SABERES A PARTIR DE FILMES: CONTRIBUIÇÕES PARA A CIÊNCIA, SOCIEDADE E O ENSINO
}

\section{THE DIALOGUE BETWEEN KNOWLEDGES FROM FILMS: CONTRIBU- TIONS FOR SCIENCE, SOCIETY AND EDUCATION}

\author{
Fábio Gabriel Nascibem ${ }^{1}$
}

\begin{abstract}
Resumo: Verificamos que as discussões na sociedade têm tendido a extremos: há visões em que negam totalmente a primazia da explicação científica e, por outro lado, visões que centram toda validade na ciência. Defendemos uma que se estabeleça diálogo entre saberes. Levantamos algumas questões: Como pode ser abordado o tema do diálogo entre saberes? Quais potencialidades? Quais contribuições para o ensino e para a sociedade tais discussões podem trazer? Nosso objetivo neste artigo é esclarecer temas relacionados ao diálogo entre saber científico e saber popular à luz de teorias da filosofia da ciência a partir de duas obras cinematográficas. As obras que analisamos foram: o "Escolarizando o Mundo - O último fardo do homem branco" e o filme "1984". Ambos fornecem subsídios para uma discussão madura do tema, com potencialidades para a sociedade, por meio de uma postura que privilegie diálogos, bem como para o Ensino de Ciências.
\end{abstract}

Palavras-chave: Saber Científico; Saberes Populares; Obras Cinematográficas.

\begin{abstract}
We note that discussions in society have tended to extremes: there are views that totally deny the primacy of scientific explanation and, on the other hand, views that focus all validity in science. We support a dialogue to be established between knowledge. We raise some questions: How can be addressed the issue of dialogue between knowledge? What potential? What contributions to education and society can such discussions bring? Our objective in this article is to clarify themes related to the dialogue between scientific knowledge and popular knowledge in the light of theories of the philosophy of science from two cinematographic works. The works we analyzed were: the "Schooling the World - The White Man's Last Burden" and the film "1984". Both provide subsidies for a mature discussion of the theme, with potential for society, through a posture that favors dialogues, as well as for Science Teaching.
\end{abstract}

Keywords: Cinematographic Works; Scientific Knowledge; Popular Knowledge.

\section{Introdução}

Este artigo é fruto de uma série de conferências e aulas proferidas por mim nos cursos de Pedagogia e Licenciatura em Biologia, da UNICAMP, no ano de 2019, como resultado de alguns anos pesquisando o tema do diálogo entre saberes, especialmente os saberes populares e o saber científico, desde a iniciação científica, passando pelo mestrado e atualmente no doutorado (NASCIBEM; VIVEIRO, 2015; NASCIBEM, 2019; NASCIBEM; VIVEIRO, 2020, no prelo).

\footnotetext{
${ }^{1}$ Doutorando em Ensino de Ciências e Matemática, PECIM/UNICAMP. Universidade Estadual de Campinas (UNICAMP), Campinas-SP, Brasil. Email: fnascibem@yahoo.com.br.
} 
DOI: https://doi.org/10.33238/ReBECEM.2020.v.4.n.3.24661

Temos defendido a adoção de uma postura de moderação frente a extremos: de um lado a centralização em um único saber, denominada por Santos (2002) de uma monocultura de rigor do saber, da qual a ciência é portadora de verdade única e é inquestionável, também chamada de cientificismo, e que acarreta várias visões distorcidas sobre o que de fato seria algo consensual sobre ciência, de acordo com a filosofia da ciência.

Por outro lado, também não se trata da negação científica, exercício que vem ocorrendo com frequência em nosso país desde a polarização política e a adoção de fontes não-seguras de consulta, as ditas fake news, o revisionismo histórico e, em alguns casos, a preferência pelo senso comum em detrimento à ciência, entre outros.

Assim sendo, buscamos um caminho em que se reconheça que é na pluralidade, que explica melhor a diversidade do mundo. Ora pode ser melhor usar referenciais pautados na ciência, como nos ambientes acadêmicos, da produção de vacinas e remédios, de estudos sociológicos sobre a sociedade, e assim por diante. Ora o contexto pode mostrar que o saber mais válido pode ser um saber popular, tal qual verificamos na área ambiental, em que se percebe uma relação direta entre povos tradicionais e a conservação ambiental (SANTOS, 2006), para citar um exemplo. Os saberes mobilizado por um povo ou por seus portadores revelam a cultura mobilizada por estes; cultura esta que guia a visão de mundo, bem como as ações, pois uma atitude é sempre guiada pelas referências e pela cultura, pelo modo de pensar.

Embora o contexto ambiental tenha uma frente de trabalho científico de extrema qualidade e com frentes de pesquisa consolidados, verificamos que o saber tradicional e popular contribui muito para a conservação de áreas florestais, o que certamente contribui imensamente com o debate. Recuperar esta sabedoria parece de extrema relevância.

Importante salientar que, como estamos tratando de um trabalho de âmbito científico, estamos lendo aos demais saberes sobre esta óptica. Ainda sobre esta questão, não se trata de um saber substituir outro, mas que, a decisão que o contexto impele possa ser tomada em vistas a um determinado corpo de conhecimento. Neste sentido, ora o saber popular pode ser acessado, ora o científico.

Tomemos outro exemplo, agora da pandemia do novo coronavírus (Sars-CoV2). Neste contexto está claro que as melhores decisões são tomadas em base do conhecimento científico. Já, quando olhamos para o contexto da agricultura e sustentabilidade, talvez, ótimas decisões podem ser tomadas quando olhamos para a agroecologia, a enxertia, a rotação de culturas, que são técnicas populares. 
DOI: https://doi.org/10.33238/ReBECEM.2020.v.4.n.3.24661

Neste sentido, toda centralização é uma violência cognitiva (SANTOS, 2002; LEFF, 2009a, b, 2010a, b, 2011, 2015; FEYERABEND, 2011). Urge então que se traga a discussão sobre o diálogo entre saberes e se conceitue melhor como ele ocorre. Neste âmbito, nós levantamos as seguintes questões: Como pode ser abordado o tema do diálogo entre saberes? Quais potencialidades? Quais contribuições para o ensino e para a sociedade tais discussões podem trazer? Assim, nosso objetivo, neste artigo, é esclarecer temas relacionados ao diálogo entre saber científico e saber popular à luz de teorias da filosofia da ciência a partir de duas obras cinematográficas.

Pretendemos contribuir com as discussões a respeito do tema, uma vez que se trata de algo relevante, e também que passamos por um período social no Brasil efervescente, com muitas posturas extremadas. Assim, trazemos a contribuição a partir de uma reflexão teórica seguida da apresentação de duas obras cinematográficas para que possam emergir valores que fomentem a discussão de temas relacionados à natureza da ciência e do diálogo entre saberes.

\section{O diálogo entre saberes}

Nesta seção iremos discutir aspectos teóricos conceituando o que tem sido melhor aceito na comunidade científica sobre o que é o saber científico; a seguir faremos o mesmo para o saber popular. Então, traremos um concatenado sobre diálogo recíproco entre estes saberes. À luz destas discussões, terminaremos a seção com uma reflexão da pluralidade de saberes na sociedade contemporânea.

A respeito do saber científico, em Nascibem e Viveiro (2015, p. 288), temos que:

[...] o conhecimento científico é definido na literatura a partir de diferentes perspectivas. São considerados científicos os conhecimentos produzidos por instituições científicas, de pesquisa, e que seguem rígidos métodos para lhe atribuir confiabilidade e lhe diferir dos conhecimentos não científicos. Têm como objetivo explicar os fenômenos da natureza, da sociedade, etc., e baseia-se em problemas de pesquisa muito bem definidos e que são esmiuçados seguindo metodologias e processos na busca de resultados para o problema inicial (NASCIBEM; VIVEIRO, 2015, p. 288).

Deste modo já conseguimos diferenciar o saber científico dos demais, pois suas marcas são: a presença de métodos, muitas vezes pautadas pelo rigor nas suas determinações, uma linguagem própria e um processo de validação de seu conhecimento, que é feita pela avaliação pelos pares. Outros conhecimentos não possuem o mesmo rigor nas 
DOI: https://doi.org/10.33238/ReBECEM.2020.v.4.n.3.24661

suas determinações, e o seu processo de validação é mais pautado no dia a dia, como os saberes populares (LAKATOS; MARCONI, 2003). Exceção feita para o saber filosófico, que tem uma natureza reflexiva, porém dotada de profundo rigor.

Entendemos ciência como um corpo de conhecimento, pautado por uma linguagem própria, por uma forma de avaliação peculiar de avaliação dos seus conhecimentos, que valida o conhecimento produzido, dotado por rigor e métodos. $\mathrm{O}$ pensamento científico, ou seja, o saber científico, é emanado deste corpo de conhecimento e mobilizado pelas escolas e instituições científicas.

Quando se centra no saber científico como único saber válido, temos uma monocultura de rigor do saber (SANTOS, 2002). Mas, Feyerabend (2011) afirma que os xamãs e os povos antigos já possuíam conhecimentos a respeito de plantas medicinais e outras tantas explicações. Muitas delas vieram anos depois a serem sistematizadas e corroboradas pelo saber científico. Portanto, não é possível conceber uma visão de um saber que detenha toda primazia do conhecimento humano plural e, portanto, diverso. Diz ainda que a ciência, bem como os saberes populares, podem se valer uns das explicações dos outros, mas jamais deve haver imposições culturais.

Poderia haver algum pensamento de que estamos defendendo um caminho ponderado, mas usando Paul Feyerabend, um dito anarquista epistemológico como referencial, portanto um extremista. Ocorre que o próprio afirma que sua obra "Contra o Método" é fruto de uma conversa com Imri Lakatos, outro filósofo da ciência, da qual ambos dissertavam sobre a natureza e progresso do pensamento científico. Então, o autor faz uma ironia de que parecia que a comunidade pautava-se em um "tudo vale", bastando que se tivesse uma boa retórica para convencer os pares (FEYERABEND, 2011).

Esta observação da parte de Feyerabend (2011), nos lembra que sua obra é um ensaio provocativo à comunidade científica, sobre o que parecia ser o progresso da ciência, para suscitar reflexões. Em outras palavras, o progresso científico parecia pautado mais na retórica do que em um método rigoroso.

Feyerabend neste contexto havia combinado que escreveria o ensaio e submeteria a Lakatos, para que este pudesse o refutar, de acordo com suas concepções, fato que não ocorreu porque Lakatos acabou falecendo antes.

Entendendo este contexto, parece minimizar o uso de tal obra em um artigo que busca optar por um caminho de ponderação, uma vez que ele é uma crítica à comunidade acadêmica. Absorvemos a contribuição de Feyerabend (2011) no sentido de propor 
DOI: https://doi.org/10.33238/ReBECEM.2020.v.4.n.3.24661

que na ciência não residem todas as verdades, mas que os conhecimentos tradicionais e populares já traziam muitas contribuições para a humanidade, conforme dito acima.

Feita esta observação, e caminhando ainda mais, “[...] os saberes populares, por sua vez, são aqueles que as pessoas possuem acumulados durante sua vida e servem para explicar e compreender aquilo que as cerca" (NASCIBEM; VIVEIRO, 2015, p. 289). Além disso, possuem uma linguagem concreta e são transmitidos de geração em geração através da imitação e da oralidade. Uma confusão recorrente é confundi-lo com o senso comum. Mas, Chassot (2011) conceitua que o senso comum atinge a todos indistintamente, uma vez que somos leigos na maioria dos campos de conhecimento. Enquanto isso, um saber popular é aquele que está ligado a fazeres e práticas do dia a dia (LAKATOS; MARCONI, 2003; CHASSOT, 2011).

Em resumo, o saber popular seria aquele saber dotado culturalmente, transmitido de geração em geração, geralmente relacionado às práticas do dia a dia; dotado de uma linguagem simples e concreta e que expressa os feitos da comunidade para a solução de problemas práticos e cotidianos.

Conhecendo melhor as principais características dos saberes, - podemos saber como estes dialogam. Em Nascibem e Viveiro (2020, no prelo), refletimos que o diálogo entre o saber científico e os saberes populares se dá com uma região de aproximação, em que ambos contribuem reciprocamente, havendo distanciamentos, à medida em que se tem um pensamento de ciência como único saber válido ou conquanto que o saber popular se distancie, se aproximando de visões de senso comum ou pautando suas explicações em saberes mágicos.

Um exemplo advindo da prática foi quanto estudamos os saberes provenientes de um grupo de moradores de um assentamento rural, no interior de São Paulo, no que tange à medicina popular (NASCIBEM; VIVEIRO, 2015). Na ocasião, tivemos como principais resultados que os saberes dos moradores advêm da prática do dia a dia, ou então de acumularem estes saberes vindos de seus antepassados. Questionamos o que usavam para práticas de cura (chás, emplastos, pomadas, etc.), bem como quais plantas, se havia rituais, entre outras questões. Posteriormente, comparamos com artigos científicos da área de farmacologia. Grande parte dos usos dos populares se mostrou convergente com os dados presentes nos artigos da área científica. Não tinham a mesma terminologia, por óbvio, mas há claramente a explicação do fenômeno por lentes diferentes. 
DOI: https://doi.org/10.33238/ReBECEM.2020.v.4.n.3.24661

Imagem 1: Círculos fleckianos modificados. Fonte: Nascibem e Viveiro (2020, no prelo, adaptado).

Podemos explicar melhor a região de contribuição recíproca entre os saberes através dos escritos de Ludwick Fleck (2010), que afirma que os conhecimentos humanos podem ser explicados por meio de dois grandes círculos: o círculo exotérico - que contém as pessoas que são leigos mais ou menos instruídos de uma determinada área; e o círculo esotérico - que contém as pessoas que são especialistas naquela mesma unidade de conhecimento.

As relações ou diálogos entre os saberes destes dois círculos podem ser explicados por meio do seguinte esquema, baseado em Fleck (2010) e com nossa contribuição, à medida em que temos compreendido o que distancia os saberes de sua zona de diálogo.

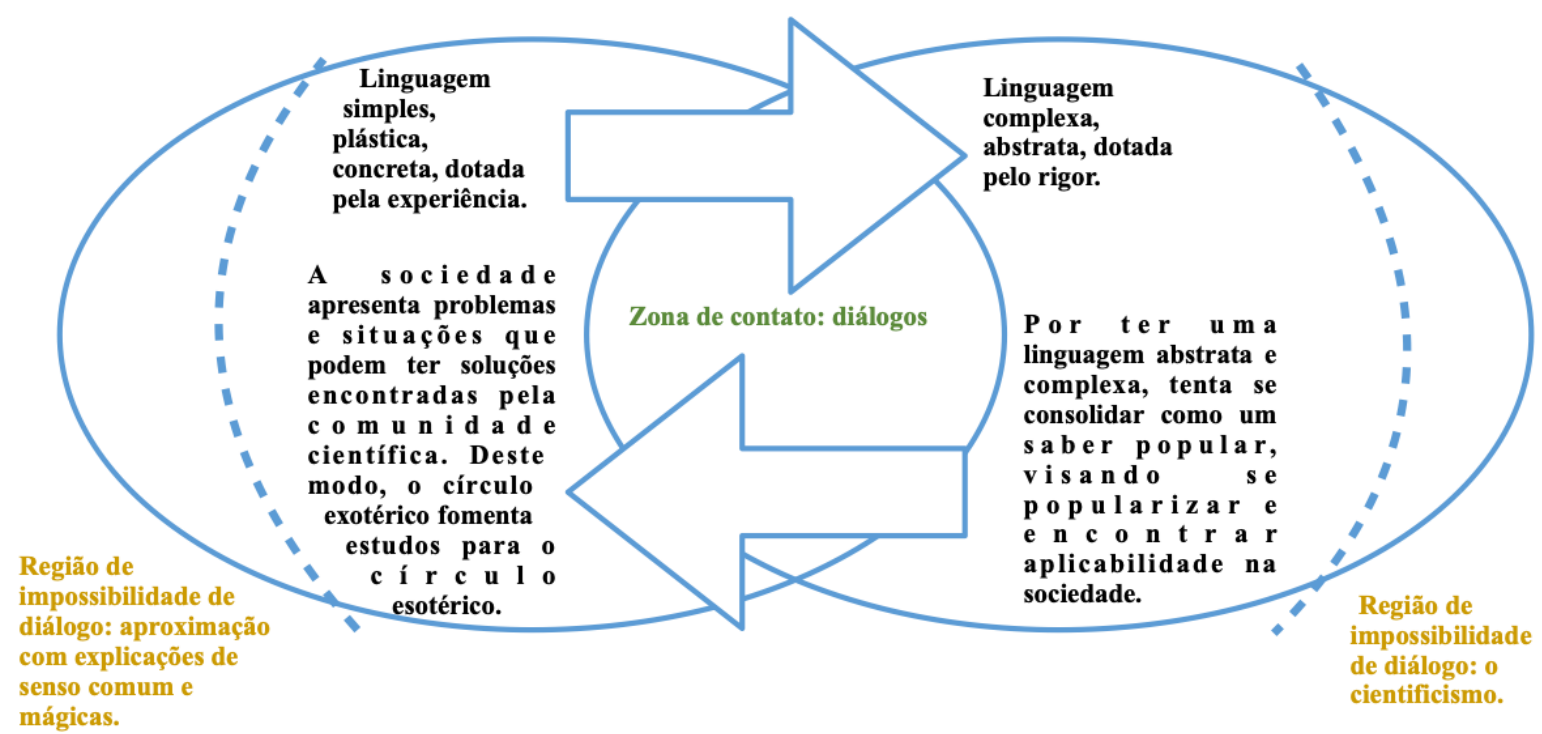

Círculo exotérico

Círculo esotérico

Na estrutura em que ilustramos tais diálogos, podemos observar que há uma zona de aproximação, em que as explicações tanto de leigos mais ou menos instruídos e de especialistas dialogam. Talvez, isso se dê com formas de linguagem diferentes, mas há um esforço de diálogo. Na medida em que há extremos tanto de um lado quanto de outro, há impossibilidades.

Na região de contato, a chave está na linguagem. O saber científico, contido no círculo esotérico, que é abstrato e distanciado da tessitura social, tem o bônus de oferecer rica sistematização, rigor e distanciamento para lidar com problemas de pesquisa. Em contrapartida, tem o ônus de por si só, não encontrar grande procedência e aplicabi- 
DOI: https://doi.org/10.33238/ReBECEM.2020.v.4.n.3.24661

lidade entre a população geral. O saber popular, contido no círculo exotérico, tem uma linguagem simples e concreta, dotada pela experiência e, muitas vezes, não possui linguagem para explicação dos seus fenômenos, tampouco distanciamento. Por outro lado, oferece esta linguagem plástica, entendida como sendo uma linguagem concreta e facilmente entendida no cotidiano, para que os conceitos científicos possam se popularizar. O modo em que ocorre a popularização depende de vários fatores que não vamos aprofundar aqui, como a divulgação científica. Os saberes populares também grandes problemas para serem lidos pela óptica científica. Assim, ocorre a retroalimentação entre os saberes.

Boaventura de Sousa Santos (1989, 1995, 2002, 2007, 2009) denomina este processo de contribuição recíproca entre os saberes de Ecologia de Saberes, para o qual todas as hierarquias a priori são quebradas, e o saber mais válido é aquele que melhor se aplique no contexto. Por certos contextos, o melhor saber será o científico. Para outras determinações, os saberes populares podem se aplicarem de uma forma melhor.

Muitas vezes, no entanto, o diálogo é impossível, pois, o saber científico é hierárquico a priori, possuindo para si todo prestígio e formando um abismo entre os outros saberes considerados periféricos, como os saberes populares e tradicionais (SANTOS, 1989, 1995, 2002, 2007, 2009). Então, sugere-se a tradução - movimento pelo qual todos os saberes são colocados em diálogo, dentro de um contexto para que a prática mostre qual se adeque melhor entre todos os saberes, formando uma ecologia de saberes, e a hierarquia agora seria atribuída de uma forma pragmática, sendo que o contexto a determina (SANTOS, 2009).

Numa visão mais utópica, Enrique Leff (2009a, b, 2010a, b, 2011, 2015) propõe uma hibridização radical entre os saberes, uma mudança de óptica de mundo. Sua visão é que o saber resultante seja uma mistura de vários outros. Assim, os diferentes atores são emancipados, colocados em diálogo. Esta mudança de óptica é utópica, uma vez que pressupõe a mudança dos padrões societários e perpassa pela mudança do sistema capitalista, uma vez que ele possui uma simbiose, colocando como centro o saber científico.

Harari (2016, 2018a, b) contribui afirmando que a base do progresso da sociedade capitalista tem uma simbiose com a ciência, uma vez que é o saber científico que melhor se adequa às aspirações do tecnicismo, do progresso e da produção incessante. 
DOI: https://doi.org/10.33238/ReBECEM.2020.v.4.n.3.24661

Assim, a ciência trouxe inequivocamente teorias, técnicas e tecnologias que movimentam o sistema capitalista que, por sua vez, é alimentada pelo sistema.

Então, para Leff (2009a, b, 2010a, b, 2011, 2015), a utopia da hibridização radical dos saberes é o que poderia trazer a verdadeira emancipação para povos tradicionais e populares. Sem isso, sempre haveria algum tipo de epistemicídios.

Ainda neste sentido, Harari $(2016,2018 \mathrm{a}, \mathrm{b})$ afirma que o futuro traz alguns desafios para a humanidade, tais como: evitar os problemas associados ao antropoceno ${ }^{2}$, causado pela destruição ambiental, e lidar com a obsolescência tecnológica. Sobre a primeira, está claro que os povos tradicionais e populares têm mostrado que seus saberes se adequam melhor à conservação ambiental (SANTOS, 2006), do que os saberes técnicos e pautados exclusivamente no lucro. Sendo assim, uma postura de diálogo entre saberes, se abrindo a outras culturas, pode nos mostrar caminhos para lidar com esta problemática. Sobre a segunda, urge pensar em como evitar mais epistemicídios, pois a obsolescência se dá porque o nível de exigência de conhecimentos tecnológicos será tanta, com tamanha especialização, que se não houver preocupação e ações em relação a isso, poderá criar uma geração de inúteis.

Por um lado, discutimos as contribuições recíprocas entre saberes como um caminho de ponderação em meio à extremos e já refletimos sobre o extremo da centralização no saber científico.

Ocorre que têm sido verificado outro fenômeno na sociedade brasileira atual, e outras também, que é o negacionismo científico. Pessoas que utilizam fake news para se comunicar e se informar Ainda há aquelas que preferem pautar suas explicações de mundo a visões conspiratórias ou de cunho duvidoso, como o terraplanismo, o revisionismo histórico, a descrença quanto ao aquecimento global ou o ataque às vacinas (VASCONCELLOS-SILVA; CASTIEL; GRIEP, 2015).

Harari (2018) nos lembra que estamos na era da pós-verdade, em que verdade parece ser aquilo que cada um em seu íntimo crê como verdadeira. Portanto, neste âmbito, há um negacionismo de fatos históricos, explicações da natureza ou da sociedade, porque tudo o que importa é o que sujeito crê e pensa. À medida em que isso ocorre, há

\footnotetext{
${ }^{2}$ Grosso modo, o antropoceno seria o período geológico atual, marcado pela pressão humana sobre o ambiente; pressão essa que abre a possibilidade de extinção da espécie humana, devida a catástrofes ambientais, tal como mudanças climáticas e suas consequências.
} 
DOI: https://doi.org/10.33238/ReBECEM.2020.v.4.n.3.24661

aproximação destes saberes advindos das práticas do dia a dia, portanto populares, com o senso comum, sendo impossível o diálogo.

Deste modo, em suma, podemos sintetizar que um diálogo entre saberes é entendido como uma aproximação em que tanto o saber popular como o científico possam dialogar, com ganhos recíprocos para ambos. O saber científico fornece uma linguagem distanciada e métodos rigorosos para solução de problemas da sociedade. Ao passo que o saber popular fornece problemas a serem resolvidos no âmbito científico e uma linguagem concreta, que permite que conhecimentos possam se popularizarem. As contribuições deste diálogo são: a) valorizar atores portadores dos saberes; b) fugir de violências cognitivas e sensação de não saber; c) potencializar o uso dos saberes cotidianos no ensino, tornando-o mais proximal da realidade dos e das estudantes; d) trazer um ambiente de debate em que se possa superar fontes ruins de informação - as ditas fake news, evitando o senso comum. Dito isso, apresentamos exemplos de filmes que possam suscitar o debate apresentado anteriormente.

\section{Análise de obras cinematográficas como potencialidade para discussão da temá- tica}

Nesta seção, vamos discutir dois exemplos de filmes, sendo um de gênero documentário e uma obra cinematográfica, que abordam temas que julgamos possíveis para introdução da pluralidade de saberes. O primeiro deles é um documentário intitulado: "Escolarizando o Mundo: o Último Fardo do Homem Branco (ESCOLARIZANDO, 2011)"; a seguir, o filme adaptado do livro homônimo "1984” (NINETEEN EIGHTYFOUR, 1956).

A análise dos filmes obedeceu ao critério de emergir falas dos filmes e trazer contextos das mesmas, para serem lidos à luz dos conceitos sobre a natureza do saber popular e do saber científico, bem como as teorias que assentam o diálogo recíproco entre eles. Destacamos a presença de extremismos, de um lado o cientificismo e de outro o negacionismo, como propostas de discussão para o ensino de ciências.

Nas conferências proferidas para as turmas de biologia e pedagogia da UNICAMP, bem como nas aulas proferidas no contexto da disciplina de Didática das Ciências, do curso de Licenciatura em Biologia, para alunos do último ano, da UNESP/ Campus Jaboticabal, tenho adotado a apresentação das obras na íntegra, ou mesmo recortes, seguidas de discussão das mesmas em vistas à natureza da ciência e ponderando 
DOI: https://doi.org/10.33238/ReBECEM.2020.v.4.n.3.24661

a questão da importância do diálogo entre saberes. Os trechos dos filmes expressos na próxima seção são alguns exemplares.

O uso das obras cinematográficas deve ser compreendido como um meio contextualizar as discussões sobre diferentes saberes. Outros exemplares de obras podem vir a serem identificados que atendam ao mesmo pressuposto.

\subsection{O documentário "Escolarizando o Mundo: o Último Fardo do Homem Branco"}

A possibilidade de reflexão a partir deste documentário tange ao extremo de centralização dos saberes no saber científico, uma monocultura de rigor do saber (SANTOS, 2002). Resgatamos para tanto, algumas ideias dispostas em NASCIBEM (2019), que vêm a seguir.

Visualizando efeitos de uma centralização de um saber em detrimento à pluralidade, temos que no documentário dirigido por Carol Black, intitulado "Escolarizando o mundo: o último fardo do homem branco" (ESCOLARIZANDO, 2011), é possível constatar o quanto é audaciosa a proposta de imposição cultural. Por um lado, os ocidentais, autointitulados missionários, com a missão de aculturar o restante do mundo. Em outra visão os indianos, que veem suas culturas esmagadas pela cultura ocidental, vendida como única capaz de promover a verdade.

Seguindo nesta direção, o documentário apresenta a visão ocidental do processo, da qual é "fardo do homem branco" civilizar o restante do mundo, retratando a situação dos povos tradicionais da Índia. Segundo a visão ocidental, os saberes tradicionais e populares destes povos são atrasados e devem ser substituídos pelo saber científico, para trazê-los para o mundo moderno, onde as aspirações são sempre materiais, de acumulação de bens e dinheiro.

$\mathrm{O}$ efeito disto pode ser visto nas crianças indianas entrevistadas, que mal sabem sobre sua própria cultura ou identidade. Elas são proibidas de se comunicarem em língua local, sendo que nas escolas é permitido apenas se comunicar na língua inglesa, pois esta é a "língua universal".

Os frutos desta ocidentalização são sentidos por pessoas dessas comunidades tradicionais, das quais reproduzimos algumas falas contidas no documentário:

[1] Eu era mais feliz antes do que agora que as crianças foram embora para estudar, elas precisam estudar. Antes todos ficávamos juntos (ESCOLARIZANDO, 2011, adaptação nossa). 
DOI: https://doi.org/10.33238/ReBECEM.2020.v.4.n.3.24661

[2] Eu não sei nada, quando alguém vem perguntar algo, mando falar com meus filhos, eles foram à escola (ESCOLARIZANDO, 2011, adaptação nossa).

Estas duas falas são de uma senhora camponesa das regiões montanhosas da Índia. Antes do advento da ocidentalização, as pessoas eram supostamente mais felizes por viverem em comunidade, gerações atrás de gerações, onde comungavam conhecimentos e vivências.

Há, entretanto, uma quebra cultural brusca, o saber local é desacreditado e as crianças vão embora para grandes cidades para "aprenderem" o saber ocidental, em uma tentativa de universalizar o mundo em torno do conhecimento científico. A segunda fala é contundente, sendo comum ver pessoas acharem que não sabem nada por não serem proficientes no saber científico.

Esta violência cognitiva é fruto de uma disputa que opõe de um lado os saberes populares e tradicionais - que são característicos das populações, e obtidos através da transmissão de gerações e gerações; e de outro, a pretensão da ciência ocidental em universalizar o mundo em torno de um saber supostamente superior, detentor de verdades.

Ainda no documentário, a falsa ideia de que, por meio dos costumes ocidentais, dentre os quais o conhecimento científico tradicional, as sociedades tidas como atrasadas pelas lentes ocidentais irão prosperar, é desmentida. A maioria dos recém-formados em universidades indianas não consegue emprego, o que os frustra, deprime e lhes trazem sentimento de fracasso.

Por outro lado, as pessoas, ao se sentirem pertencidas à cultura, com seus saberes, com seu espaço e seus territórios, tendem a possuir um sentimento de completude, felicidade, bem-estar e realização.

Aqui, o que propomos não é a ideia de ingenuamente romantizar a vida no campo, e tampouco os saberes populares ou tradicionais. A nossa ideia é que todo centramento de saber ignora possibilidade de diálogos e gera epistemicidios. Para problematizarmos, traremos a seguir a fala importante do pesquisador Wade Davis, antropólogo e etnobotânico de origem colombiana-canadense, entrevistado no filme:

Se me acidentasse, gostaria de ser levado ao médico, não a um xamã africano. (ESCOLARIZANDO, 2011, adaptação nossa).

A partir desta fala, corroboramos que não se trata ingenuamente de desprezar o saber científico, que claramente traz e trouxe enormes contribuições para o desenvolvi- 
DOI: https://doi.org/10.33238/ReBECEM.2020.v.4.n.3.24661

mento da humanidade. A medicina moderna, por exemplo, pode ser muito mais eficiente em certos tratamentos que o tratamento milenar através de plantas, mas este não é o ponto em discussão, e sim, a violência cultural.

O que propomos não é esquecer um saber em detrimento a outro, mas sim, estabelecer diálogos, uma vez que acreditamos que estes diálogos são enriquecedores para ambos os saberes.

No caso do documentário, a visão expressa em meados do século $\mathrm{XX}$, denominada de cientificismo, e retratada como um extremo nesta obra, é aquela que a ciência seria a resposta para todo problema da humanidade, sendo um conhecimento civilizador, visto como fardo do homem branco a sua transmissão. Esta visão é claramente problemática, pois gera uma série de problemas, como: a sensação de não saber por parte de pessoas que não são iniciadas neste saber, mas que são profundamente conhecedoras de uma série de outras culturas. Este sentimento pode gerar infelicidade e um sentimento de não pertencimento.

Pode ser, então, que seja prudente uma profunda mudança de lógica, sendo que a visão capitalista, que acarreta sérios problemas ao ambiente, não possa mais ser "remendada" e, desta forma, não podemos esperar que se solucionem os problemas por ela justapostos. Sendo assim, é importante se ponderar e estabelecer novas visões.

A visão portanto que defendemos é uma postura que se valha no diálogo recíproco entre saberes. O contexto deve ser definidor da decisão de qual saber utilizar. Claro que o conhecimento traz progresso. Entretanto, tal obra nos mostra que não se pode haver um sentimento civilizador e higienista, que substitui todas as culturas, relegando a estas o esquecimento. Pensamos que pode haver contribuições recíprocas, como temos demonstrado neste artigo.

\subsection{O clássico 1984}

O filme “1984” (NINETEEN EIGHTY-FOUR, 1956), dirigido por Michael Radford foi uma adaptação do livro homônimo, um clássico de George Orwell (2009), gravado em 1984. A reflexão que ele traz é sobre o outro extremo, que é o negacionismo científico.

Ocorre em um exercício imaginativo de Orwell para conceber uma sociedade no pós-guerra, uma vez que o livro original foi escrito em 1949, em que há consolidação de um regime totalitário, para qual o grande ditador é denominado de "Grande Irmão". 
DOI: https://doi.org/10.33238/ReBECEM.2020.v.4.n.3.24661

Neste contexto, o da sociedade fictícia de Oceânia, há grande opressão, sendo que todos os moradores são vigiados por uma espécie de televisão, que além de vigiar as pessoas em suas próprias casas, ainda transmite as ordens do ditador. Ordens que vão desde as informações de nível governamental até de influência na ordem da vida pessoal do povo, como ordenar o momento de se exercitar.

A repressão e a intimidação cumprem um grande papel para consolidação do regime do Grande Irmão, mas há outro fator que nos interessa mais neste momento, que é o negacionismo científico e a pós-verdade.

Naquela sociedade, um dos principais ministérios era o Ministério da Verdade, cuja sua função era reescrever as notícias e fatos, dando uma versão oficial para qual o Grande Irmão era sempre vitorioso, detentor de todas as qualidades, sempre exitoso, uma espécie de divindade.

Para tanto, é necessário que se tenha uma ciência fraca, totalmente destruída. Ao eliminar completamente a objetividade e o rigor científico avançamos para o subjetivismo, em que tudo é passível de interpretação, mesmo que isso signifique ignorar todos os dados e fatos.

Ocorre que, como há um ministério da verdade, que expressa a única visão aceita pelo regime, em detrimento aos fatos, também relega-se a capacidade das pessoas pensarem. Não há margem para a objetividade, para a criatividade, tampouco ao raciocínio abstrato, constituintes importantes para a formulação de ideias pautadas no pensamento científico. Se as pessoas não têm margem para o pensamento científico, logo o que resta é aceitar passivamente a suposta verdade transmitida pelo organismo estatal.

Imaginemos que se um grupo científico tentasse se instalar neste país. Ele enfrentaria inúmeros problemas: a) não teria fomento financeiro estatal para a pesquisa, o que asfixiaria e inviabilizaria a sequência das pesquisas; b) investidores externos não se sentiriam a vontade para investirem nestes empreendimentos, pois um país totalitário nunca é seguro para investimentos; c) parte dos fanáticos do regime perseguiriam os cientistas por trazerem uma visão certamente crítica ao Grande Irmão; d) haveria certamente repressão pelo regime; e) as pesquisas não encontrariam aplicabilidade nenhuma na sociedade em questão.

Neste sentido, uma sociedade em que há graus parecidos com o cenário hipotético de oceânia, certamente com uma ciência enfraquecida as pessoas tendem a se pautarem em informações pouco confiáveis. 
DOI: https://doi.org/10.33238/ReBECEM.2020.v.4.n.3.24661

Ora, alguém pode afirmar que não crê no aquecimento global ou na primazia da vacina porque não se simpatiza. Ou ainda, é possível ignorar dados de satélite que indicam o desmatamento na Amazônia, porque os dados não agradam.

Ao reinventar a história, os membros do governo (no âmbito do filme) constroem narrativas que forjam a mentalidade da população, que uma vez desprovida qualquer capacidade de senso crítico, crê que toda verdade provê de Grande Irmão.

Está claro que este filme, bem como o livro, tratam de um caso extremo. Porém, toda vez que há fenômeno de negacionismo e pós-verdade, estamos sujeitos à ocorrência de calamidades ou da consolidação de regimes totalitários.

O que podemos extrair de reflexões a partir desta obra é que o extremo negacionista é também uma arma poderosa de opressão, pois usa o próprio oprimido como ferramenta da opressão. A ciência, bem como a filosofia, são fomentadoras de senso crítico. Uma vez perdido isso, há fanatismos e visões conspiratórias, sendo impossível a possibilidade de diálogo e de argumentação.

Na seção seguinte vamos discutir estes valores discutidos nas obras cinematográficas à luz das teorias explicitadas na seção 1 .

\section{Discutindo valores relacionados às obras}

As obras trazidas representam exemplos de um repertório para discussão do tema do pensamento humano e suas facetas. Construímos agora uma discussão sobre alguns valores que consideramos importantes e que estão dispostos nas obras para subsidiar discussões quanto à natureza da ciência.

Primeiro, a obra "Escolarizando o Mundo - O último fardo do homem branco", trata-se de uma obra irônica e provocativa, que representa a visão extrema de centralização no pensamento científico, chamado por Santos (2002) de uma monocultura de Rigor do Saber.

Esta visão de que um único saber válido, o científico pode ser considerada como uma grande violência cultural. Os efeitos puderam ser sentidos, trazendo sensação de não-pertencimento e de não-saber naquelas pessoas retratadas.

Ainda é uma visão bastante excludente, pois de acordo com os escritos de Leff (2009a, b, 2010a, b, 2011, 2015), os atores não portadores de saber, logo são excluídos completamente da possiblidade da reivindicação de direitos e do exercício da cidadania. 
DOI: https://doi.org/10.33238/ReBECEM.2020.v.4.n.3.24661

Não se trata de negar a ciência neste caso, mas de reconhecer outros saberes. As diferentes culturais também possuem primazia e importância. Como discute Feyerabend (2011), não podem haver imposições. O caminho mais adequado parece ser de estabelecer diálogos.

Não se discute que a ciência é o saber sistematizado e acumulado historicamente pela sociedade. Porém, deve-se evitar o esvaziamento cultural. O saber científico não é um saber civilizador, como pretendiam os britânicos naquele contexto, mas pode ser um excelente aliado na leitura do mundo.

Consideramos uma boa abordagem aquela de Paulo Freire (1979, 1981, 1987, 1996) que partia da realidade dos educandos, dialogando com seus saberes, a partir dos quais, chamados de temas geradores, para introduzir o saber científico. Assim, a construção do conhecimento era conjunta, jamais imposta e violentadora. Pouco a pouco as pessoas iam se apropriando das suas realidades de forma crítica, algo que viria a ser chamado de conscientização, e enxergando horizontes e novos caminhos, processo denominado de utopia. No fim, as pessoas conservavam suas raízes, mantinham-se culturalmente pertencidas, mas agora enxergando de uma forma crítica e sistematizada.

A finalidade do ensino para Freire $(1979,1981,1987,1996)$ parece confluir para o mesmo que Leff (2009a, b, 2010a, b, 2011, 2015), que seria uma mudança de lógica societária, emancipatória, para qual os saberes pudessem ser colocados em pé de igualdade. Para tanto, é necessário abrir espaço para outro modelo social e econômico, de modo que as aspirações não sejam apenas o progresso incessante e o lucro.

Por outro lado, o filme bem como o livro “1984” (NINETEEN EIGHTY-FOUR, 1956) apresenta outra face da moeda do extremismo epistemológico, que seria o negacionismo científico. Ali, parece haver a cristalização de uma sociedade que nega a ciência. Isso porque com o enfraquecimento da comunidade acadêmica, do sistema educacional, da capacidade das pessoas pensarem criticamente, leva à condição de submissão.

Os moradores de Oceânia eram incapazes do exercício da cidadania. Tudo era controlado pelo Estado Totalitário imposto pelo Grande Irmão, inclusive o pensamento. O Ministério da Verdade tinha a incumbência de queimar jornais e reescrever notícias e a própria verdade.

O negacionismo científico é a negação de qualquer objetividade e de qualquer relação de causa e efeito entre fatos e modelos explicativos, dando espaço total para a subjetividade. 
DOI: https://doi.org/10.33238/ReBECEM.2020.v.4.n.3.24661

Evidentemente que a subjetividade é algo importante e está presente no fazer ciência. Mas, quando se perde de vista toda objetividade e qualquer compromisso com dados abre-se totalmente o espaço para a imaginação e a construção de narrativas e absurdos podem acontecer.

Temos visto o crescimento do fenômeno das fake news, bem como de teorias conspiratórias. Por mais que se tente argumentar com base em fatos, tecnologias, explicações científicas, os portadores de tais informações estão convictos de que estão com a verdade, configurando a impossibilidade de se debater.

O grande acesso à informação através da democratização do acesso promovida pela internet leva pessoas a opinarem e entrarem em contato com diversas e diferentes informações, sem mesmo terem conhecimento sobre aquilo que lhes é informado. A internet é uma plataforma aberta que permite manifestações com pouco ou nenhum controle.

Sobre a pós-verdade, situação em que as pessoas pautam suas convicções exclusivamente no que pensam e excluem qualquer possibilidade de diálogo com o contraditório, por ferirem suas convicções é muito importante adotar uma postura moderada, pois, qualquer sorte de posturas extremadas impede diálogos, e como mostrado, todo radicalismo têm sido problemático, seja pela violência cultural ou, mesmo, pela pósverdade.

Nesta zona de contato que propomos, há grandes oportunidades de ganhos recíprocos para os saberes. Consideramos ambos os filmes e tantos outros uma boa oportunidade de trazer a discussão à tona. Há potencialidades para cursos de formação de professores para que reflitam sobre qual o papel da ciência, dos saberes, qual a finalidade da escola e pensarem maneiras de ensinar de um modo plural. Ou ainda, para cursos em que se discuta História e Filosofia da Ciência, ou sobre a evolução do pensamento científico.

Para níveis de Educação Básica, sugerimos que o livro, bem como o filme “1984” (NINETEEN EIGHTY-FOUR, 1956) pode ser um recurso de trabalho interdisciplinar, comungando as disciplinas, como: história (pelo período histórico), sociologia (pelo ambiente social), arte (pela estrutura literária da obra e do autor, no pensamento contemporâneo), filosofia (pelos valores) e ciências (pela história e a importância da ciência na construção do pensamento crítico). 
DOI: https://doi.org/10.33238/ReBECEM.2020.v.4.n.3.24661

Para o ensino de ciências, seria importante trazer discussões acerca de um ensino mais investigativo, que reflita sobre a realidade dos alunos, sobre a dialocidade de saberes, pela checagem de informações, sobre informações seguras vs fake news, o processo de validação dos feitos científicos - que o conferem confiabilidade -, entre outros. Também é recomendável tratar das distorções quanto ao pensamento e o trabalho científico dispostas em Gil-Peres e colaboradores (2001), bem como os consensos sobre ciências. Tais caminhos sinalizam para uma postura de um pensamento crítico e cidadão.

Outros filmes são possíveis e que servem para os mesmos propósitos, como: Rutherford 451 e Admirável Mundo Novo. Ambos são distopias que tratam do totalitarismo, da disseminação de informações falsas e sem compromisso com a realidade, com a tirania e outros assuntos. No fim, ambas podem também vir a ser empregadas para tratarem de tais extremos e reforçarem a importância da ciência.

\section{Considerações finais}

Diante de um quadro em que a sociedade tem pautado suas discussões em extremos: por um lado a visão que centraliza como um único saber válido, a ciência; por outro lado, o negacionismo científico, em que o conhecimento científico é desacreditado, mesmo que traga contribuições relevantes, e substituído por visões em alguns casos prejudiciais, como, por exemplo, o movimento anti-vacina; temos defendido uma postura de moderação, de diálogo entre diferentes saberes.

Disto, trouxemos algumas questões: Como pode ser abordado o tema do diálogo entre saberes? Quais potencialidades? Quais contribuições para o ensino e para a sociedade tais discussões podem trazer? Assim nosso objetivo neste artigo foi de discutir duas obras cinematográficas que tratam de temas relacionados ao diálogo entre saberes à luz de teorias da natureza da ciência.

Pensamos ter atingido com o objetivo assinalado, uma vez que tais filmes fomentaram uma discussão madura, de natureza epistemológica entre os saberes. Neste caso, enfocamos nos saberes populares e no saber científico. Analisamos duas obras: O filme “1984” (NINETEEN EIGHTY-FOUR, 1956), que apresenta uma possível consequência do negacionismo científico e destruição do pensamento crítico; e também a obra "Escolarizando o Mundo: O Último Fardo Homem Branco" (ESCOLARIZANDO, 2011), que traz a tona a violência cultural do cientificismo. 
DOI: https://doi.org/10.33238/ReBECEM.2020.v.4.n.3.24661

$\mathrm{Na}$ sociedade brasileira contemporânea, este debate se faz necessário, pois de um lado, as instituições científicas vêm sendo colocadas em xeque por meio de retóricas agressivas e negacionismos. Pessoas parecem acessar fontes sem a mesma pretenção da busca por rigor e confiabilidade. Por outro lado, há a necessidade em se valorizar outras fontes de saberes, uma vez que nossa sociedade é plural e miscigenada. Pensamos que tais filmes suscitam o debate da necessidade do diálogo entre saberes, cujas bases teóricas trouxemos contribuições neste artigo. Assim, acreditamos que as obras analisadas têm grande potencialidade na discussão para a sociedade, bem como para o Ensino de Ciências.

Por fim, esperamos que tais escritos possam estimular reflexões e estudos para a comunidade interessada, seja por meio de discussões de natureza filosófica, por meio da epistemologia da ciência, seja de natureza educativa, por meio do Ensino de Ciências, da arte - através da apreciação das obras cinematográficas, mas, sobretudo, um estímulo à diversidade cultural da humanidade. Pensamos, por fim que pode haver outras obras que cumpram o mesmo papel aqui assinalado, então que seja estimulada a criatividade também neste sentido.

\section{Agradecimentos}

Agradeço à Coordenação de Aperfeiçoamento de Pessoal de Ensino Superior (CAPES) pelo apoio financeiro à pesquisa e à Profa. Dra. Alessandra Aparecida Viveiro por todos estes anos de orientação desde a Iniciação Científica até o doutorado, sem os quais seriam impossíveis tais reflexões.

\section{Referências}

CHASSOT, A. Alfabetização científica: questões e desafios para a educação. 5. ed. Editora Unijuí: Ijuí, 2011

ESCOLARIZANDO o mundo. O último fardo do homem branco. Direção: Carol Black. Recuperado em 20 agosto, 2018: de https://www.youtube.com/watch?t=370\&v=6t_HN95-Urs.

FEYERABEND, P. Contra o método. $2^{\mathrm{a}}$ ed. São Paulo: Editora UNESP, 2011.

FLECK, L. Gênese e desenvolvimento de um fato científico. Tradução de George Otte e Mariana Camilo de Oliveira. Belo Horizonte: Fabrefactum, 2010. 
DOI: https://doi.org/10.33238/ReBECEM.2020.v.4.n.3.24661

FREIRE, P. Conscientização: Teoria e Prática de libertação: Uma introdução ao pensamento de Paulo Freire. $1^{a}$ edição. São Paulo: Cortez \& Moraes, 1979.

FREIRE, P. Ação Cultural para a liberdade e outros escritos. $5^{\text {a }}$ edição. Rio de Janeiro: Paz e Terra, 1981.

FREIRE, P. Pedagogia do oprimido. $17^{\text {a }}$ edição. Rio de Janeiro: Paz e Terra, 1987.

FREIRE, P. Pedagogia da autonomia. Saberes necessários à prática educativa. $25^{\text {a }}$ edição. São Paulo: Paz e Terra, 1996.

GIL-PÉREZ, D. et al. Para uma imagem não deformada do pensamento científico. Ciência $\boldsymbol{\&}$ Educação, v. 7, n. 2, p. 125-153, 2001.

HARARI, Y. N. Sapiens: Uma Breve história da humanidade. $33^{a}$ ed. Tradução Janaína Marcoantonio. Porto Alegre: L\&PM, 2018a.

HARARI, Y. N. Homo Deus: Uma breve história do amanhã. $1^{a}$ ed. Tradução Paulo Geiger. São Paulo: Companhia das Letras, 2016.

HARARI, Y. N. 21 lições para o século 21. $1^{\text {a }}$ ed. Tradução Paulo Geiger. São Paulo: Companhia das Letras, 2018b.

LAKATOS, E. M.; MARCONI, M. A. Fundamentos de metodologia científica. 5. ed. São Paulo: Atlas, 2003.

LEFF, E. Ecologia, capital e cultura: a territorialização da racionalidade ambiental. Edição. Petrópolis: Editora Vozes, 2009a.

LEFF, E. Complexidade, racionalidade ambiental e diálogo de saberes. Educação \& realidade, Cidade de publicação, v. 34, n. 3, p.17-24, colocar o mês abreviado, se houver. 2009 b.

LEFF, E. Discursos Sustentáveis. Edição. São Paulo: Cortez, 2010a.

LEFF, E. Pensar a complexidade ambiental. In: LEFF, E (Coor.). A complexidade ambiental. 2. ed. São Paulo: Cortez, 2010b. Deve colocar a pagina inicial e final separadas por hífen.

LEFF, E. Complexidade, interdisciplinaridade e saber ambiental. Revista Olhar de Professor, v.2, n.14, p. 309-335, colocar o mês abreviado, se houver, 2011. Recuperado em 5 Outubro, 2018 de http://www.revistas2.uepg.br/index.php/olhardeprofessor. 
DOI: https://doi.org/10.33238/ReBECEM.2020.v.4.n.3.24661

LEFF, E. Saber Ambiental: sustentabilidade racionalidade, complexidade, poder. 11. ed. Petrópolis, RJ: Vozes, 2015.

NASCIBEM, F. G.; VIVEIRO, A. A. Saberes Populares ConsCiência: Uma investigação sobre a medicina popular. In: Encontro Nacional de Pesquisa em Educação em Ciências, 10, 2015, Águas de Lindóia. Anais... Águas de Lindóia: ABRAPEC, 2015. Disponível em http://www.abrapecnet.org.br/enpec/x-enpec/anais2015/busca.htm?query=nascibem

NASCIBEM, F. G. Protagonismo ambiental em práticas de arborização: elementos motivacionais, saberes e fazeres de atores sociais. Dissertação (Mestrado em Ensino de Ciências e Matemática) - Universidade Estadual de Campinas, Programa Multiunidades em Ensino de Ciências e Matemática, Campinas, 2019.

NASCIBEM, F. G.; VIVEIRO, A. A. no prelo. Saber Popular e Saber Científico: Uma convergência Possível? Editora Blucher Open Acces: São Paulo, 2020.

NINETEEN EIGHTY-FOUR. Filme 1984: O futuro do mundo. Direção de Michael Anderson. Recuperado em 10 Janeiro, 2020 de https://www.youtube.com/watch?v=g2-rxLTVdxI.

ORWELL, G. 1984. Tradução de Alexandre Hubner e Heloísa Jahn. $10^{\text {a }}$ reimpressão. Companhia das Letras: São Paulo, 2009.

SANTOS, B. S. Introdução a uma Ciência Pós-Moderna. $6^{\text {a }}$ ed. Porto: Afrontamento, 1989.

SANTOS, B. S. Toward a new common sense: Law, Science and Politics in the Paradigm Transition. $1^{\text {a }}$ edição. Routledge: New York, 1995.

SANTOS, B. S. Para uma sociologia das ausências e uma sociologia das emergências. Revista Crítica de Ciências Sociais. Coimbra, v. 63, p. 237-280, 2002.

SANTOS, B. S. Renovar la teoría crítica y reinventar la emancipación social (Encuentros en Buenos Aires). $1^{a}$ edição. Buenos Aires: Consejo Latinoamericano de Ciencias Sociales CLACSO, 2006.

SANTOS, B. S. Para além do pensamento abissal: das linhas globais a uma ecologia dos saberes. Revista Crítica de Ciências Sociais, Coimbra, v. 78. p. 3-46, Outubro. 2007.

SANTOS, B. S. Um Ocidente Não-Ocidentalista?: A filosofia à venda, a douta ignorância e a aposta de Pascal. IN: SANTOS, B.S; MENESES, M.P (Orgs). Epistemologias do Sul. $1^{\text {a }}$ edição. CES: Coimbra, 2009a. p. 445-486. 
DOI: https://doi.org/10.33238/ReBECEM.2020.v.4.n.3.24661

SANTOS, B. S. De las dualidades a las ecologías. $1^{\text {a }}$ edição. La Paz: REMTE-Red Boliviana de Mujeres Transformando la Economía, 2012.

SANTOS, B.S; MENESES, M.P.. Prefácio. In SANTOS, B.S; MENESES, M.P (orgs). Epistemologias do Sul. CES: Coimbra, 2009. p. 215-242.

VASCONCELLOS-SILVA, P. R.; CASTIEL, L. D.; GRIEP, R. H. A sociedade de risco midiatizada, o movimento antivacinação e o risco do autismo. Ciênc. saúde coletiva, v. 20, n. 2, 2015.

Recebido em: 25 de abril de 2020

Aceito em: 20 de julho de 2020 